\title{
COMMENTARY
}

\section{Disaster medicine: the caring contradiction}

\author{
David Crippen ${ }^{1 *}$, Charles Krin², Dean Lorich ${ }^{3}$ and Ken Mattox ${ }^{4}$
}

\begin{abstract}
The nature of mankind is a concern for those in need. Disasters, both natural and manmade, have been with us since the beginning of recorded history but media coverage of them is a relatively new phenomenon. When these factors come together, there is great potential to both identify and serve the sick and injured. However, the mass media by its nature tends to enhance the humanistic aspect of rescue while minimizing the practical problems involved. We describe a recent scenario in Haiti that puts some of these complications into a practical perspective.
\end{abstract}

On such a full sea are we now afloat. And we must take the current when it serves, or lose our ventures.

Shakespeare

From Armenia in 1987 to Indonesia in 2004, to New Orleans in 2005, and now to Haiti in 2010, we have embarked on a sobering journey in public health logistics. Previous standards of disaster response crumbled when tested. New standards are now tested in real situations rather than in theory [1].

Even in an unforgiving environment, the principles of the Federal Emergency Management Agency (FEMA) still apply to the the command structure, albeit in a modified form [2]. We learned the difficult lesson that trauma is not the major issue following a disaster [3]. The traditional influx of $a d$ hoc rescue teams flooding into the area actually hinders progress, as it did after the 9/11 disaster in New York City [4]. Safety provided support personnel and security of supply channels have always rivaled the good intentions of would-be rescue teams [5].

Mass media commentary on disasters tends to soften the horror of the reality by reflecting a compassionate

\footnotetext{
*Correspondence: crippen+@pitt.edu

'University of Pittsburgh Medical Center, Department of Critical Care Medicine,

644s Saife Hall, 3550 Terrace Street, Pittsburgh, PA 15261, USA

Full list of author information is available at the end of the article
}

fantasy: the illusion that human altruism conquers all [6]. This media apparition also inadvertently reinforces the similar illusion that all assistance is effective assistance. We share the experience of a well-intentioned medical group whose involvement puts the usual media coverage into a realistic perspective.

Surgical and critical care teams may have awareness of unique supply and transportation issues but they have little oversight of on-site security, infrastructure, command, re-supply, or support systems. A motivated, committed and well-equipped trauma team traveled to Haiti several days after the earthquake for the purpose of medical assistance. Their destination was a designated hospital to establish comprehensive emergent surgical intervention for orthopedic injuries.

The multidisciplinary team of surgeons and support personnel departed with an extensive medication list and comprehensive equipment, including a functioning portable operating room and postoperative recovery area (D Lorich, personal communication). They planned to quickly replenish expended equipment by private jet through their corporate connections.

On arrival, the team found that the expected ground support from Partners in Health was nonexistent. Their flight logistics were either delayed or cancelled. On ultimate arrival, the designated site did not have functional operating facilities. Among other problems, there was no running water and only a limited electrical supply.

Their backup option was the Community Hospital of Haiti, which turned out to be more functional but overloaded with patients. Anesthesia machines were nonfunctional; other needed materials were in short supply or inadequate for their needs, and there was only a ragtag group of voluntary health providers who had made it there on their own.

The team found no one in charge at the site. They had established the first functional acute care hospital in the disaster area, yet no one arrived to assess and coordinate the activities. The military could not or would not protect the resupply of equipment or protect from pilfering.

There was no security for the team, despite promises to provide it from the New York City Police Department and the Fire Department, City of New York. Procedures were begun on a hit or miss basis, quickly generating a need for replenished supplies. The re-supply plane landed 
and its supplies were hijacked somewhere between the airport and reaching the team.

Having completed more than 100 procedures over several days, the team was exhausted and disillusioned. On the morning of the team's proposed departure, a huge influx of new patients forced a lockdown of the facility, closing its gates to the outside, resulting in the crowd becoming angry and hostile. That same morning, the team noted that many of their operative patients were looking septic and there was no demonstrable medical follow-up available. Supplies were not being replenished and safety was a huge concern.

Ultimately, the team decided to make their way to the Port 'a Prince airport through the assistance of a private hospital benefactor. Armed Jamaican soldiers were necessary to escort the team past the hostile crowd surrounding the hospital. On making their way back to the airport in the back of a pickup track, the team hailed a commercial plane carrying cargo to Montreal and had a private jet pick them up there.

In retrospect, the team's assessment of the situation is as follows. The amount of human devastation was impossible to comprehend before arrival. The lack of a medical infrastructure and support from Haitian physicians was underestimated and underassessed. Finally, there was a lack of organization on the ground and a lack of any security at all at the hospital.

The problems illustrated by this team's experience are encapsulated by Michael DeBakey's famous comment: 'All the circumstances of war surgery thus do violence to civilian concepts of traumatic surgery' - a statement that remains as true today as it did in 1942 when he developed the first Mobile Army Surgical Hospitals [7].

The ultimate solutions to these problems are more subtle, requiring a long-term commitment on the part of both individuals and organizations to partner with experienced charitable nongovernmental organizations around the globe [8]. These partnerships will provide the teaching, training and, ultimately, the technology for disaster areas to become more reliant on their own resources. This development will include not only medical outreach, but also infrastructure development.
This exchange will facilitate personnel from the more developed countries to learn how to live and work under unfamiliar austere circumstances. This new learning curve will require a paradigm shift in the attitudes of the volunteers as they adapt to the requirements of the new and potentially hostile environments.

This is but one team's experience. They learned lessons that should be used to guide other future teams who are not already part of a unified, integrated infrastructure. The team's experience also points out both the major problems associated with modern disaster response and a possible solution.

\section{Competing interests}

The authors have no competing interests

\section{Author details}

'University of Pittsburgh Medical Center, Department of Critical Care Medicine, 644s Saife Hall, 3550 Terrace Street, Pittsburgh, PA 15261, USA. Emergency Medicine, 2620 North Westwood Boulevard, Poplar Bluff, MO 63901, USA. ${ }^{3}$ Orthopedic Surgery, Hospital for Special Surgery, 520 East 70th Street Starr Pavilion, 2nd Floor New York, NY 10021, USA. ${ }^{4}$ Department of Surgery, Baylor University Medical Center, One Baylor Plaza, Houston, TX 77030, USA.

Published: 22 March 2010

\section{References}

1. Gostin LO, Hanfling D: Preparedness for a catastrophic emergency; crisis standards of care. JAMA 2009, 302:2365-2366.

2. FEMA Independent Study Program [http://training.fema.gov/IS/NIMS.asp]

3. Crippen D: Concluding thoughts on the new nature of disaster management. Crit Care 2006, 10:111. [http://ccforum.com/content/10/1/111]

4. Martinez C, Gonzalez D: The World Trade Center attack. Doctors in the fire and police services. Crit Care 2001, 5:304-306.

5. Mattox KL: Hurricanes Katrina and Rita: role of individuals and collaborative networks in mobilizing \& coordinating societal and professional resources for major disasters. Crit Care 2006, 10:205 [http://ccforum.com/content/10/1/205]

6. Saxena DB, Shah HM, Mishra P: Media response to disaster. Indian J Med Sci 2009, 63:28-29.

7. DeBakey ME: Military surgery in World War II - a backward glance and a forward look. N Engl J Med 1947, 236:341-350.

8. Krin CS, Giannou C, Seppelt IM, Walker S, Mattox KL, Wigle RL, Crippen D: Appropriate response to humanitarian crises. BMJ 2010, 340:C562.

doi:10.1186/cc8895

Cite this article as: Crippen D, et al.: Disaster medicine: the caring contradiction. Critical Care 2010, 14:133. 